\title{
Levels of incompetence. On the place of rationality in an irrational world
}

\author{
Aleksander Kobylarek - Sohaib Alam - Maria Gaziova - Martyna Madej
}

DOI: 10.18355/XL.2022.15.01.06

\begin{abstract}
The phenomenon of incompetence as an interdisciplinary subject requires multiple analyses embracing various spheres of life, and scientists whose knowledge is limited to only one discipline may face difficulties in capturing the core of the issue. This article is based on a meta-reflection inspired by the discourse revealed in posthumanist and post-pandemic reality. Its aim is to define sources of irrationality, areas of ignorance and, above all, levels of incompetence to reveal the primary categories. One of the problems standing in the way of development is a lack of interest, which leads to ignorance. A limited number of experiences and stimuli different from those in our everyday lives can lead us to a perception of the world solely from our own perspective. In the political sphere, cooperation between the authorities and specialists for the good of the community is crucial. The greed for power and money is fatal, causing numerous abuses, scientific knowledge becomes "inconvenient", so it is easier to ignore it. A lack of unanimity among researchers and a divergence of views, cause the people who are not fully aware of how science works to begin to doubt it, which increases the obstinacy of their own views. It is impossible not to question and to systematize knowledge completely; the problem arises at the level of the dissemination of knowledge. Moreover, emotions and the phenomenon of resentment play one of the key roles in rationality, and controlling them and continuing education can reduce the phenomenon of incompetence.
\end{abstract}

Key words: incompetence, irrationality, post-soviet society, interdisciplinary, politics, common-sense knowledge, post-scientific society, resentment

\section{Introduction}

The successes of populism at the beginning of the 21 st century needs to be treated as symptoms of an intellectual and moral crisis in developed democracies (Malo, 2021). Interestingly, it is not only young democracies in Central and Eastern Europe that are being seduced into this crisis, but also more experienced political systems with strong safeguarding mechanisms, as in the case of the United States, Austria, Italy, and the United Kingdom.

Intellectuals are amazed at the bizarre, ill-considered choices of others and the changes taking place around them. Thinking people, driven by rationality, cannot understand the conditions that lead to such irrational choices (Applebaum, 2020; Pavlikova, 2019).

The fundamental problem is that understanding the phenomenon of making irrational choices and acting against one's basic interests requires complex interdisciplinary analyses on several levels. Scholars, usually coming from specific scientific traditions, specializing in a specific subject, representing a specific scientific school and thinking along subject lines, may have difficulty in grasping the essence of problems whose

XLinguae, Volume 15 Issue 1, January 2022, ISSN 1337-8384, eISSN 2453-711X 
explanation requires a meta- or at least a trans-disciplinary approach. Psychology, sociology, political science, economics or the philosophy of science cannot explain the complex problems of the post-rational world without referring to other sciences, or at least to each other.

Another difficulty is the overlapping and infiltration of different levels, concepts and areas, and it is often difficult to define clear boundaries. The identification of the processes and dependencies themselves is often a great problem. This does not mean that we should give up, but it is primarily interdisciplinary researchers who have a chance of making accurate diagnoses. They, in turn, are not always understood by those who are limited by discipline. This observation is especially important for healthy scientific communication, which should not be limited to a group of narrowly specialized "experts" in the subject, who are unable to go beyond self-defined limitations and a kind of incompetence in the field of interdisciplinary (Collins, 2014). The article is a conceptual work that corresponds to the publications of cited authors and also refers in its methodological aspect to referenced masters such as Z. Bauman and A. Applebaum. Thus, the reader will not find direct references to either primary or secondary data, which is so characteristic of research articles, especially those prepared in the positivist paradigm. The authors also did not wish to bore readers by duplicating what can already be found in the work of other scholars and instead focused on a synthetic presentation drawn from their own categories. We are aware that this may cause a sense of insufficiency in the reader, but at the same time, we believe that it will be an incentive for in-depth independent studies.

\section{The basic level of incompetence. Common sense knowledge}

One of the most important problems of somebody lost in the windings of contemporaneity/postmodernity/post-rationality is a lack of interest (Keyes, 2004). We are not born specialists in a particular problem, but we become specialists by studying a specific field, a strictly defined area of knowledge, or some fragment of reality that is part of a larger whole.

It is no different in the case of everyday life. In order to function well in the complex reality of the world around us, we need good preparation and appropriately formed intellectual properties, cognitive powers, consciousness, intellect, awareness, or plain common sense (Such \& Szczesniak, 2002).

Experiencing everyday life and the so-called pedagogy of places (Majchrzak, 2012), work on one's ego in primitive groups, reflection, the ability to take the perspective of the Other in a harmonious combination with a critical look at everything (including oneself) - all these constitute a basis for thinking, building a personal picture of the world and arriving at wisdom (understood as the opposite of wisdom) (Lukaszewski, 2018). Somebody immersed in experiencing everyday life can easily become lost and adopt a narrow perspective in which their existential situation will be their only point of reference. It is as if they were the navel of the world, or as if other perspectives were by definition worse because they are beyond real experience.

Common-sense knowledge, however, is limited to a specific place and space (Wojciszke \& Rotkiewicz, 2018). Its value increases if it becomes the genesis and basis for the creation of proto-scientific knowledge, which is more general, by going beyond experiencing the world as it is here and now. Thus, treating common sense knowledge as a reference point for building even these personal theories must be by 
definition limited. A comprehensive vision of the world certainly cannot be built on this basis.

Unfortunately, many people, especially the less educated, with limited powers of critical thinking, with a narrow perspective, intellectually lazy or dumbfounded, are unable or unwilling to go beyond experiencing everyday life (we can call it the sin of failure to develop). On the other hand, this leads to cause-and-effect relationships being explained by charlatans, fortune-tellers, and pseudo-authorities, eager for fame or profit (Stiegler, 2012). Their success comes in reaching out and guaranteeing an accessible language, understandable to the uneducated and therefore all the closer to everyday experience, as well as appealing to fears, hopes and needs. Such people present a false image of science, presenting it in a distorted mirror as being too theoretical, detached from reality, incomprehensible, and therefore useless. Thus, they seek to present themselves as more anchored in reality and closer to the real experience of the common man (Sunstein, 2006).

\section{The intermediate level of incompetence. Political practice}

The political sphere is a mixture of the elements of ideology, science, a specific ethical system, and the techniques of governing (Reykowski, 2020). It seems that the implementation of an ethical system, which is included in the party's ideological manifesto, should not cause major difficulties after winning the elections and requires only consistency and an appropriate level of technical efficiency in the implementation of the election program. Obstacles often arise, however, from the pressure of lobbyists and the will to maintain power at all costs, especially if the political representatives have no scruples (Cerovac, 2014).

Realized values are of particular importance for political practice, and the governing authority reveals its true intentions the moment it begins to implement them (Alaverdov, 2020). Then it becomes clear whether the declared system of values is reflected in actions or whether it merely remains a kind of ideological decoy for the confused electorate.

If political representatives act with the public good in mind, science is essential to them, both when it provides know-how/doxa knowledge and for a deeper understanding of phenomena and processes in episteme form (Jashapara, 2004). In order to act for the good of the community, one has to go beyond the knowledge emanating from that community. It is necessary to seek the cooperation of apolitical specialists and experts free from ideological excess, who will apply their knowledge and experience and will be able to use their skills to support the development of the community. And we are thinking here of both the local community, equally national and supranational because we assume that nations and societies truly develop in cooperation and not against each other. Regarding oneself as part of an ecosystem, a larger social system, a political community is a condition for the implementation of a political philosophy leading to the improvement of the quality of life for citizens and the achievement of prosperity in various categories.

This is generally our hope when voting for political representatives. Our hope is that they will rise above individual interest and not see politics as an opportunity to easily get rich quick, and use their position as an opportunity to engage in unethical or even illegal activities. Unfortunately, when political leaders view their position as

XLinguae, Volume 15 Issue 1, January 2022, ISSN 1337-8384, eISSN 2453-711X 
privileged and feel that they are allowed more than ordinary citizens, then they are moving further and further away from the communities which they are meant to serve, treating them like a flock of sheep ready for fleecing. The more privileged they feel, the more they tend to break legal and moral standards (Galinsky \& Schweitzer, 2016). In such a situation, party ideology becomes a cover for pursuing particular interests. Big words are used to hide the intellectual void and justify abuses made in the name of a specifically defined "higher good", which becomes just an empty slogan. This leads to the greatest ideas becoming bankrupt (Wojciszke \& Rotkiewicz, 2018).

Scientific knowledge, especially that relating to social processes and phenomena, becomes dangerous, so it is better to ignore it, portray it in a bad light, or even ridicule and fight against it. The hallmark of such political systems is the persistent claim that there are various theories about specific phenomena or concepts (such as the rule of law, democracy, social justice), and therefore different approaches and understandings are possible. Hence the lack of social consensus is something supposedly normal and cannot be an obstacle to socially unacceptable activities.

In such a regime, science and scientists are treated in an instrumental way. Political representatives reveal only such research results or interpretations that can justify their actions. They also select a suitable group of scientific advisors who, being in the service of the authorities, endorse the solutions proposed by the rulers with their authority, and if necessary, provide appropriate explanations. Such scholars, for academic titles or privileges, sell themselves to the service of political parties and ideologies, and the more they engage in such a foul game, the more their scientific independence becomes a grotesque delusion.

To sum up, an incompetent authority (that is, an authority acting against the public good) cannot be scientifically oriented, because knowledge and wisdom are not values placed at the top of its hierarchy. Science usually even becomes an obstacle in achieving narrow party goals and corruption.

Finally, an incompetent authority must continue to hide its incompetence, masking it with moral scares. Its ideology and media campaigns are used to present all failures in the right light - that they are committed by others - and to glorify even the smallest achievements of power (Tkacova, Pavlikova, Jenisova, Maturkanic, \& Kralik, 2021). The incompetence of authority also manifests itself in the specific treatment of the community as a community of supporters. Negotiation and discussion, which are the normal means of gaining consensus between various groups with different interests, hardly function under the rule of incompetent authority and, at best, their only chance of occurring is when the introduction of new regulations is associated with dramatic resistance (Savater, 2021). In this respect, incompetence manifests itself in a breaking up of the political community, creating conflicts and divisions and emphasizing differences. The anti-scientific nature of this type of governing also consists in ignoring the basic properties important for the construction of various types of community. An example of such properties might be building commitment through the joint decisions of interested circles and constructing a community by inviting them to participate in exercising power (Brandes, 2018). Opposing actions, leading to a breakdown, will sooner or later end in defeat and the necessity to bear the consequences of their actions, both at the community level and individually. But the incompetent authority is unaware of this because it surrounds itself only with acceptable scientific advisers - yes-men and conformists. 


\section{The highest level of incompetence. Lost science}

The post-scientific society really begins with the marginalization of science itself. It seems to be a paradox that we live in a society saturated with modern technologies which are the result of scientific achievements, and yet at the same time we observe a rebellion against reason in the form of anti-science movements (Jedlikowska, 2015). Ignorance, resulting from unfamiliarity with facts, concepts, and phenomena at the basic level, or manipulation at the intermediate level, is so effective because the common-sense and political way of explaining how the world functions refer to what is closer, more understandable, familiar, and emotional. Therefore, for some groups, science is, as it were, only one of many schemes for explaining the world - by no means the most important one, but somewhere on the edge of consciousness. It is the one that we reach for only when we have no explanation or personal theory at hand. It appears that in a post-scientific society, science is also not the fundamental perspective for the resistance community, which builds its identity on the basis of dissent and rebellion (Marmion, 2018). Perhaps it is this additional factor that may explain the lack of shame and the ingrained obstinacy of views. After all, identity is built in opposition in order to stand out clearly. If the whole world trusts science, then resistance communities must portray themselves as anti-science in some way in order to stand out. The question naturally arises, what has happened that irrationality is no longer a cause for shame?

A source of doubt in science lies in the scientific community itself. Doubt is the natural mental state for almost every scientist at every stage of research activity - from formulating a theory to communicating the results. We reduce uncertainty thanks to multiple triangulation, reviews, and cooperation. However, it cannot be completely reduced. It is systemic self-doubt that is part of the scientist's work.

A completely different type of undermining science is treating it as a set of metanarratives equal to other meta-narratives, including ideology, art, and biographical histories (Sokal \& Bricmont, 1998). Ostentatious disregard of other disciplines, displayed by the scientists themselves, also becomes dangerous for the entire system because if one professor questions the opinion of another, which professor is right? Maybe they are both wrong? The ordinary consumer of knowledge, for whom methodological problems are incomprehensible, will not be able to decide who is right, and in a situation of cognitive dissonance, will use the explanations available. A solution could be to establish common positions in specific areas and scientific disciplines and to disseminate the results of such discussions.

Neither is it about preaching knowledge - the persistent persuasion of a pre-adopted thesis, with a minimal amount of rational arguments. People (especially adult citizens to whom we wish to spread our message) do not like to be preached at, and they may see it as some kind of symbolic violence. Rather, we should be considering ways of disseminating knowledge and scientific achievements in society, so as to construct constantly improving communities. In other words, to invest in non-formal adult education.

XLinguae, Volume 15 Issue 1, January 2022, ISSN 1337-8384, eISSN 2453-711X 


\section{Conclusion: The rebellion of the masses, the politics of bad intentions and the}

road to the abyss

In order to fully enjoy the benefits of science, we need to be suitably prepared. An educated person not only knows about the basic scientific achievements of modern civilization but is also able to broadly describe their origin and significance and assess how much change they have introduced in people's everyday lives. If they cannot, then their education is only superficial. An under-educated person succumbs to the Dunning-Kruger effect and is convinced that the small amount of knowledge they possesses can explain deeper processes and more complex phenomena. This has little to do with rationality, as that requires exploration, a balanced approach, critical thinking, and mindfulness. On the other hand, with a relatively high average level of education in Western societies, scepticism towards science and rationality may come as a surprise. Perhaps this education is too superficial, and knowledge has not been sufficiently internalized by graduates?

The question of a lack of social capital is another problem (Lasinska, 2013). Trust and relational capital are fundamental in building healthy and intelligent societies (Sztompka, 2016). Lack of trust and strong ties between members of the community results in increased suspicion, escapist behaviour, and the formation of conspiracy theories because people think that everyone is turning against them.

A not insignificant role is played by resentment, the adhesive which binds together anger, bitterness, and a desire to retaliate. Resentment is what brings communities back together in an unhealthy way, increasing the desire to be compensated for some real or imagined harm. In general, the literature shows that weak people, who cannot find their place in reality, want revenge for whatever bad has happened to them. Sometimes it is a desire for someone to pay for being arrested in development and seeing no chance of changing the status quo.

Resentment is a mechanism that cements communities in a way similar to the principle of reciprocity but in a negative way (Tescula, 2015). Inasmuch as the psychological principle of reciprocity cements the community through a series of small favours and concessions, which in turn produce a sense of obligation, resentment is born of frustration, and at best creates a community of the wronged. Others are seen not so much as brothers and sisters but as other victims. Many studies point to resentment as a phenomenon characteristic of homo sovieticus of Central and Eastern Europe, living in retrotopia, an artificially coloured and glorified world of the past (Bauman, 2017). However, resentment resulting from a sense of injustice and being a form of non-compliance with restrictions has a global presence. If such people were to start to unite, they could create political parties and reach for power, becoming a useful tool in the hands of manipulators.

Unfortunately, there is little we can do with mechanisms such as homo sovieticus thinking and appealing to resentment. Rationality may be our only weapon, but rationality loses out to the emotions and feelings that appeal to a sense of injustice. Emotions and feelings put more pressure on our behaviour than rationality does, especially if tempers are fomented by politicians appealing to social discontent in an attempt to build support for certain social groups based on negative emotions (Jedlikowska, 2016).

The post-scientific society could be a serious challenge of our times. It is difficult to contrast rationality and erudition with such phenomena as emotionality, 
disappointment, sentiment, and conspiracy theories which people very much want to believe. Additionally, a whole range of factors supporting anti-scientific attitudes must be taken into account. In the case of young democracies in Central and Eastern Europe, it is a suspicion of the state and foreigners typical of the aforementioned homo sovieticus. In the case of Western democracies, it is the desire to rebuild national pride, values of race, location, etc. In both these cases (and many others), it is an appeal to core identity, understood specifically as independent of everything and everyone, which must be an obvious utopia, because identity becomes crystallized in confrontation with that which is foreign.

In this case, what can be done to restore rationality to its rightful place in a postscientific society? It is worth considering the mechanisms on the three different levels described earlier and to look for hints there.

First of all, it is worth identifying the properties that prevent the wise and the honest from taking action. If we are unable to dissuade people motivated by emotions from taking unreasonable actions, then it is worth for a change appealing to those who are sensible and calm and guided by rationality and science. Many of them remain in a kind of torpor, because they do not think that the stupidity around them is directly related to them. Others do not have the civil courage or determination to withstand the deluge of stupidity and manipulation. Intelligent societies and their activities need to be constructed, inspired, and supported.

Another aspect which we should promote is continuous education and improvement, put forward by intelligent, honest communities and authorities (Tkacova, Pavlikova, Tvrdon, \& Jenisova, 2021). The most developed societies in which the standard and quality of life of an average citizen are relatively high (such as the Scandinavian countries) are oriented towards the continuous education of their inhabitants. It is enough to reach for already proven patterns and work on the citizens' psyche, so that the pursuit of personal development and becoming a better person appears as the basic requirement of humanity (Harari, 2018).

The authors express the hope that the categorizations and meta-reflections presented in the article will contribute to a better understanding of the categories of incompetence and irrationality and a broadening of the analytical perspectives in the philosophy of science which, as a result, will lead to a better recognition of the sources of ignorance in the knowledge society.

\section{Bibliographic references}

Alaverdov, E. (2020). "The politicization of Islamic society in post-soviet Russia," Journal of Education Culture and Society 11(1), 303-311. https://doi.org/10.15503/jecs2020.1.303.311.

Applebaum, A. (2020). Twilight of Democracy: The Seductive Lure of Authoritarianism. New York: Doubleday Books.

Bauman, Z. (2017). Retrotopia. Cambridge: Polity Press.

Brandes, U. (2018). Social Energy: Für die Gestalter der neuen Arbeitswelt. Ein Inspiratorial. Frankfurt/ New York: Campus Verlag GmbH.

Cerovac, I. (2014). "Egalitarian democracy between elitism and populism," Journal of Education Culture and Society 5(2), 31-42. https://doi.org/10.15503/jecs20142.31.42. Collins, H. (2014). Are we all scientific experts now? Cambridge: Polity Press. 
Galinsky, A. and M. Schweitzer (2016). Friend and foe: when to cooperate, when to compete, and how to succeed at both. London: Random House UK Ltd.

Harari, Y. N. (2018). 21 Lessons for the 21st Century. New York: Spiegel \& Grau, Jonathan Cape.

Jashapara, A. (2004). Knowledge Management: An Integrated Approach. Essex: Pearson Education.

Jedlikowska, D. (2015). "What model of science? Towards the sociologically," Journal of Education Culture and Society 6(1), 43-54. https://doi.org/10.15503/jecs20151.43.54.

Jedlikowska, D. (2016). "In searching for science understanding. Applying the sociology of a science based approach," Journal of Education Culture and Society 7(2), 11-19. https://doi.org/10.15503/jecs20162.11.19.

Keyes, R. (2004). The Post-Truth Era: Dishonesty and Deception in Contemporary Life. New York: St. Martin's Press.

Lasinska, K. (2013). Social Capial in Eastern Europe. Poland an Exception? Cham: Springer International.

Lukaszewski, W. (2018). Mądrość i różneniemądrości [Wisdom and other nonwisdoms]. Sopot: SmakSłowa.

Majchrzak, K. (2012). "Places of remembrance in citizenship education," Journal of Education Culture and Society 3(1), 7-14. https://doi.org/10.15503/jecs20121.7.14.

Malo, P. (2021). Los peligros de la moralidad. Barcelona: Deusto.

Marmion, J. F. (2018). Psychologie de la connerie. Lyon: Sciences Humaines Eds.

Pavlikova, M. (2019). Existential features of Søren Kierkegaard in modern American Literature. Toronto: Kierkegaard Circle.

Reykowski, J. (2020). Disenchantment with Democracy: A Psychological Perspective. Oxford UniversityPress.

Savater, F. (2021). Política para amador. Barcelona: Ariel.

Sokal, A., \& Bricmont, J. (1998). Fashionable Nonsense: Postmodern Intellectuals Abuse of Science. New York: Picador.

Stiegler, B. (2012). Etats de choc: Bêtise et savoir au XXIe siècle. Paris: Fayard/Mille et une nuits.

Such, J. and M. Szczesniak (2002). Filozofianauki [The philosophy of science]. Poznań: WydawnictwoNaukowe UAM.

Sunstein, C. R. (2006). Infotopia. How many minds produce Knowledge. Oxford: Oxford University Press.

Sztompka, P. (2016). Kapitałspołeczny. Teoria przestrzeni międzyludzkiej [Social capital. The theory of interpersonal space]. Kraków: WydawnictwoZnak.

Tkacova, H., Pavlikova, M., Jenisova, Z., Maturkanic, P., and R. Kralik (2021). "Social Media and Students' Wellbeing: An Empirical Analysis during the Covid-19 Pandemic," Sustainability, 13(18), 10442. https://doi.org/10.3390/su131810442.

Tkacova, H., Pavlikova, M., Tvrdon, M., \& Jenisova, Z. (2021). "The Use of Media in the Field of Individual Responsibility for Sustainable Development in Schools: A Proposal for an Approach to Learning about Sustainable Development," Sustainability, 13(8), 4138. https://doi.org/10.3390/su13084138.

Tescula, D. (2015). "Nostalgia after the communist regime in Romania," Journal of Education Culture and Society 6(2), 53-68. https://doi.org/10.15503/jecs20152.53.68. 
Wojciszke, B. And M. Rotkiewicz (2018). Homo niecałkiem sapiens [Homo not quite sapiens]. Sopot: SmakSłowa.

Words: 4218

Characters: 28042 (15,58 standard pages)

As. Prof. Aleksander Kobylarek, PhD

Institute of Pedagogy

University of Wroclaw

Dawida 1/3, 50-518 Wroclaw

Poland

aleksander.kobylarek@gmail.com

As. Prof. Sohaib Alam, PhD

Department of English, College of Sciences and Humanities,

Prince Sattam bin Abdulaziz University

SharaShaad bin Moaz Street,

16244 Al Kharj

Saudi Arabia

sohaibalig80@gmail.com

Assoc. Prof. PhDr. Mária Gažiová, PhD., MBA

Faculty of Theology

The Catholic University in Ruzomberok

03401 Ruzomberok

Slovakia

Martyna Madej, BA. (corresponding author)

Institute of Political Science

University of Wrocław

Koszarowa 3, 51-149 Wrocław

Poland

martyna.madej11@gmail.com 